\title{
Experimental Limitations Using Reprogrammed Cells for Hematopoietic Differentiation
}

\author{
Katharina Seiler, Motokazu Tsuneto, and Fritz Melchers \\ Senior Research Group Lymphocyte Development, Max Planck Institute for Infection Biology, 10117 Berlin, Germany \\ Correspondence should be addressed to Fritz Melchers, melchers@mpiib-berlin.mpg.de
}

Received 10 July 2011; Accepted 27 September 2011

Academic Editor: Ken-ichi Isobe

Copyright ( $) 2011$ Katharina Seiler et al. This is an open access article distributed under the Creative Commons Attribution License, which permits unrestricted use, distribution, and reproduction in any medium, provided the original work is properly cited.

We review here our experiences with the in vitro reprogramming of somatic cells to induced pluripotent stem cells (iPSC) and subsequent in vitro development of hematopoietic cells from these iPSC and from embryonic stem cells (ESC). While, in principle, the in vitro reprogramming and subsequent differentiation can generate hematopoietic cell from any somatic cells, it is evident that many of the steps in this process need to be significantly improved before it can be applied to human cells and used in clinical settings of hematopoietic stem cell (HSC) transplantations.

\section{Introduction}

The in vitro generation of hematopoietic stem cells (HSC) and mature hematopoietic cells from embryonic stem cells (ESC) promises to provide an alternative source of cells that could replace total bone marrow cells or HSC-enriched fractions of them. This is especially necessary in the case of human cells in clinical settings for HSC transplantations. In addition, studying hematopoiesis in vitro bypasses the need of donor cells, in particular to study hematopoietic disorders in human. ESC lines can be cultured long term and allow, in contrast to HSC, homologous recombination of DNA, that is, the insertion of exogenously modified genes into the appropriate sites in the genome. Thus, genetically altered, ESC-derived HSC might allow the proper genetic repair of defective cells of the hematopoietic system, including those of the innate and the adaptive immune system. However, for transplantations of human cells histoincompatibilities between the ESC-derived HSC and the transplanted host might be the cause of transplant rejections.

Since it has now become possible to generate ESC-like induced pluripotent stem cells (iPSC) from differentiated peripheral cells $[1,2]$, HSC as well as mature hematopoietic cells might in the future be generated from differentiated cells of a patient via iPSC. Somatic cells that are either mature, fully differentiated cells or are restricted in their ability to develop into a limited collection of cell types can be induced to become pluripotent, so that they exhibit higher differentiation capacity. This process is called reprogramming. It is not yet clear whether reprogramming will always equal dedifferentiation. The original, and most widely employed method to induce iPSC from somatic cells uses ectopic expression of the transcription factors Oct-4, Sox-2, and Klf-4, either with or without c-myc $[1,3-8]$. However, concerns limiting clinical applications of patient-derived, that is, directly converted iPSC, include potential epigenetic differences between iPSC and ESC [9-18], and possible modifications of the genome by insertions and continued expression of the transcription factors that could affect the capacities of reprogrammed iPSC to properly differentiate. In our case of interest, we discuss some limitations to develop them into HSC and their differentiated hematopoietic cell lineages.

Several studies have improved the procedure of the generation of iPSC from a variety of different types of differentiated cells to find the most efficient method. In general, attempts to optimize both cell-intrinsic and exogenous factors to achieve optimal growth, survival, and differentiation requirements, first for the transfection phase and, thereafter, for the conversion from the differentiated cells to the iPSC have been made [1,3-8]. Many studies exist showing that iPSC share the characteristic of ESC, that is, they can give rise to all cell types of a proper body, proven by the development 
of chimeric animals and teratoma formation [1]. However, these qualitative analyses do not provide information about the quantitative efficiency of development. Thus, to investigate whether iPSC can replace ESC to study development and for clinical applications, efficiencies of development are needed.

Here, we summarize our experience with Oct-4/Sox2/Klf-4-transduced mouse embryonic fibroblasts (MEF), mouse bone marrow-derived (MBM) hematopoietic progenitors, and mouse fetal liver-derived preB lymphocytes in the in vitro generation of iPSC that show varying levels of continued expression of the transduced transcription factors in iPSC and in differentiating hematopoietic cells. These levels of transgenic expression relate to the potency of the iPSC to differentiate subsequently in vitro to hematopoietic cells.

Hematopoietic development from ESC and iPSC is one of the best-studied differentiation programs. Culture systems have been developed that allow the differentiation of hematopoietic lineages in vitro from ESC and iPSC [19-27] which we have attempted to optimize for myeloid, T, NK, and $\mathrm{B}$ cells [28]. However, the efficient development and maintenance of in vivo reconstituting HSC from ESC and iPSC remains challenging. For a clinically relevant procedure of generating transplantable HSC, first, the best type of differentiated cell for conversion to iPSC with the best cellintrinsic and extrinsic factors have to be found. Thereafter, improved methods need to be developed to generate and stabilize the pluripotent, long-term reconstituting potentials of transplantable HSC.

\section{Reprogrammed Somatic Cells as New Sources for the Generation of Hematopoietic Cells}

2.1. Step 1: From Differentiated Cells to iPSC. Somatic cells were first reprogrammed by somatic cell nuclear transfer [29-31]. Later, lineage-associated transcription factors were identified within a pool of 24 pluripotency-associated factors that had the potential to reprogram adult cells into pluripotent cells upon retroviral transduction [1]. Thus, transduction of mouse fibroblasts with Oct-4, Sox-2, Klf-4, and c-myc-generated iPSC by selection for Fbxo 15 activation that expressed pluripotency markers, generated teratomas upon subcutaneous injection, and contributed to different tissues upon blastocyst injection [1]. Transcription factorbased reprogramming has been optimized, so that c-myc was omitted and cells were selected with reactivation of Nanog and Oct- 4 as well as by checking the ESC-like morphology [ 4 , $6,8,32]$. Facts, hypotheses, and unresolved issues of cellular reprogramming [33] and the maintenance and change of epigenetic memory in iPSC [34] have recently been discussed extensively. As summarized by Hanna et al. [33], gene expressions and biological characteristics of iPSC may be influenced by genetic backgrounds (different strains of mice, healthy donor-derived versus patient-derived iPSC), incomplete or heterogeneous iPSC formation, additional or alternate reprogramming factors, and transgene-expressing iPSC.

In our experiments, we have used the method of retroviral transduction with three vectors that constitutively express Sox-2, Oct-4, and Klf-4, respectively, and in which the transcription factor genes are not excisable, for example, by cre/lox-mediated deletion. We have generated iPSC lines from MEFs, and MBM. All of our iPSC lines express ESCcharacteristic markers and form teratomas in vivo [28].

Continued transgene expression in our iPSC lines at different levels, even throughout differentiation to hematopoiesis in vitro, appeared possible. When this was measured, a remarkable difference became apparent. All MEF-iPSC lines showed expression patterns of the three transgenic transcription factors that were hardly above those of the corresponding endogenous genes, while all MBM-iPSC lines showed a markedly higher expression of Oct-4,Klf-4 and Sox-2. It appears that a higher threshold expression of the three factors is needed to reprogram MBMiPSC than MEF-iPSC.

Distinct differentiated cells need different culture conditions, for example, different stromal cells or other cytokines (Figure 1). While MBM-derived cells do not grow well in the iPSC condition without IL-6 and SCF, MEF do. This may contribute to our observations that the efficiencies of establishing MEF-derived iPSC are higher than that of MBMderived iPSC in our experiments. This indicates that the establishment of iPSC is more difficult if the original somatic cells from which the iPSC are intended to be induced do not fit iPSC media conditions on MEF and LIF.

The tissue culture conditions for the transduction and subsequent in vitro conversion to iPSC appear markedly different. Thus, when we consider the changes that MEF proliferating in medium alone, compared with MBM proliferating in medium substituted with SCF and IL-6 have to undergo after viral transduction to become iPSC MEF should find it easier to continue proliferation and survival in LIFsubstituted media. Maybe the higher expression of the three transduced transcription factors is favourable for the more difficult conversion of MBM to iPSC. Thus, we suggest that the ability of cells to grow in "iPSC selection media" might influence their efficiency to reprogram.

\subsection{Step 2: From ESC and iPSC to HSCs and Mature} Hematopoietic Lineage Cells. For the differentiation of ESC towards several types of mature hematopoietic cells, two protocols have been developed - the formation of embryoid bodies (EB) that form in suspension culture and the cocultivation of ESC with stromal cells. In the first protocol, ESC are allowed to grow in suspension in the absence of feeder cells and LIF, differentiate spontaneously, and form spheroidal aggregates mimicking embryonic tissues, so called embryoid bodies [35-38]. Cells within developing EB can differentiate to mature cells, including hematopoietic lineage cells $[39,40]$. Hematopoietic progenitor cells, which have the tendency to exist as mobile, nonaggregated single cells, must be freed by dissociating procedures from these $\mathrm{EB}$ aggregates.

In the second protocol, cocultivation of ESC with preadipocytic stromal cells allows a two-dimensional differentiation into hematopoietic cells without the formation of those complex aggregated structures and, thus, an easier, gentle isolation of progenitors of hematopoietic development [21, 27]. Furthermore, the use of the M-CSF-deficient stromal cell line OP9 avoids premature differentiation to myeloid 


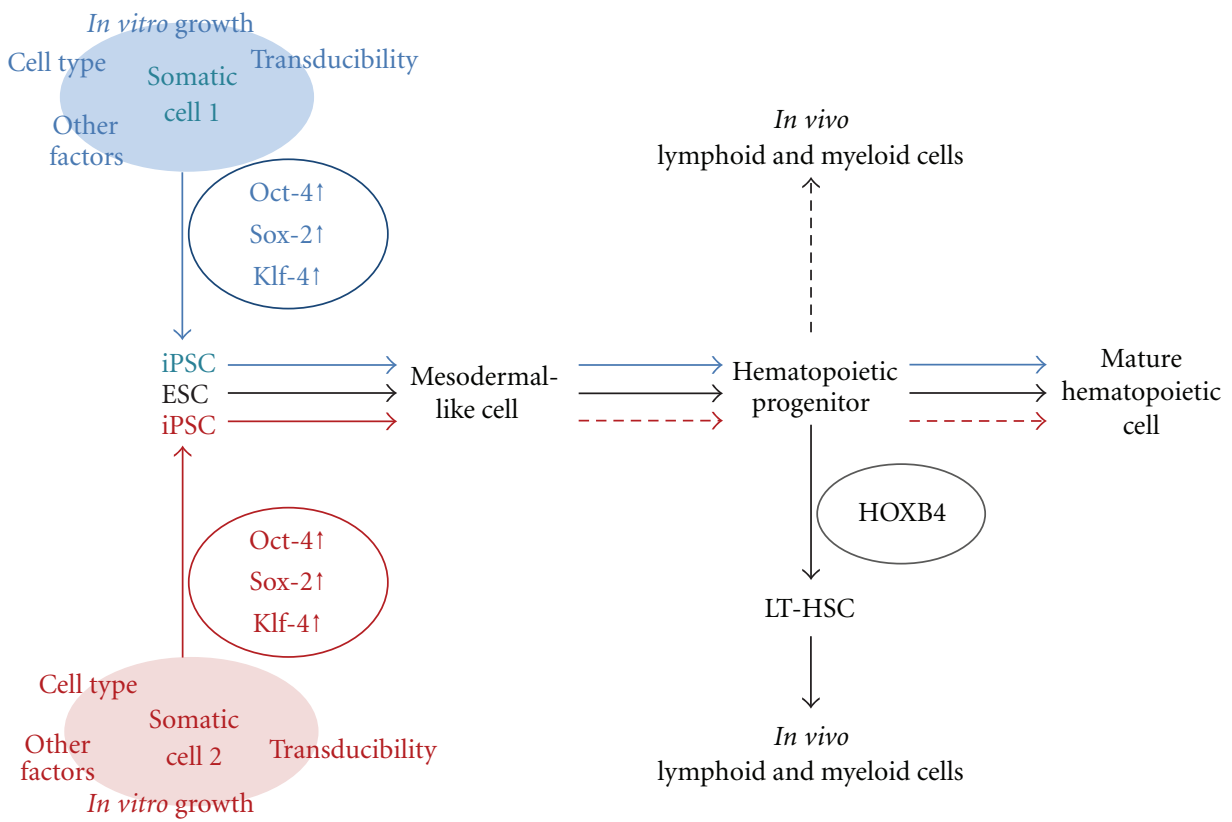

FIGURE 1: Overview of the current understanding of the efficiency to induce iPSC from different types of somatic cells, and subsequent development of iPSC into hematopoietic cells. Dashed lines implicate lower numbers of cells developing from the former cell type compared to full lines.

lineage cells and allows the development of $\mathrm{T}, \mathrm{NK}$, and $\mathrm{B}$ lymphoid cells [21]. In our in vitro differentiation experiments comparing ESC and iPSC [28] — the latter generated by retroviral transduction with Sox-2, Oct-4, and Klf-4-we did observe a reduced ability of iPSC-derived mesodermallike cells to differentiate into hematopoietic progenitors in vitro. When Oct-4, Sox2, and Klf-4 were still highly expressed in the differentiating cells. The overexpression of Sox-2 appeared to be inversely related to hematogenic potency (data are summarized in Table 1).

In conclusion, our experiments suggest-as those of others [41] - that expression of virally transduced genes must be terminated before the induction of differentiation. The three different transcription factors appear to impede hematopoietic development to different extents. While Oct4 and Klf- 4 appear to be tolerated at continuously elevated levels to generate at least progenitors and precursors of $\mathrm{T}$, NK, B, and myeloid cell development, levels of Sox-2 need to be downregulable for hematopoietic development. From these results, it appears that overexpression of the transgenic transcription factors inhibits development of Flk- $1^{+}$mesodermal to $\mathrm{CD}_{4} 5^{+}$hematopoietic progenitors. Constitutive expression has been shown by others not to affect the development of iPS cells into cells of the hematopoietic system [42, 43]. We would expect from our results that the transgenic expression of the three transcription factors in their iPSC lines should be as low as that of our MEF-iPSC lines.

If normal mouse or human somatic cells are used for the generation of iPSC the viral vectors should be deletable [44] without mutagenic consequences or should be introduced as proteins [45] or as synthetic modified mRNA [46].

\section{Generation of HSC from ESC and iPSC Still Needs to Be Improved}

Even if the procedures for the generation of iPSC will eventually be faithful and efficient enough to yield cells with the same differentiation potencies as those of ESC the subsequent efficient generation of transplantable, reconstituting HSC derived from ESC and iPSC cells still has been difficult until today. Murine iPSC can be used to generate new mouse strains in which bone marrow should, in most cases, become the source of normal numbers of long-term reconstituting HSC. In contrast, human iPSC, obviously, can not be used for such an in vivo development of HSC. Hence, the development of human HSC from ESC and iPSC must be attempted by differentiation in tissue cultures. The most successful method to obtain HSC in vitro from ESC is to transduce the cells with HOXB4 [23, 25, 47-54].

However, such retroviral modifications generate cells in which the "per cell" hematopoietic potency is still inferior to the same number of unseparated total bone marrow cells. Furthermore, retrovirally transduced cells carry the risk of mutations which might lead to malignant transformations, for example, leukaemia in the case of HOXB4 [55]. A few studies have reported transplantations of non-HOXB4transduced cells resulting in long-term engraftment of both 
TABLE 1: Differentiation of MBM- and MEF-derived iPSC lines in comparison to ESC lines. Numbers of cells indicate those developed from $4 \times 10^{3}$ undifferentiated cells (day 0). Expression levels represent amounts of mRNA determined by quantitative RT-PCR, normalized to GAPDH expression, and calculated as expression values of the respective genes in undifferentiated Bruce4 ES cells (day 0).

\begin{tabular}{|c|c|c|c|c|c|c|c|c|}
\hline Cell line & $\begin{array}{c}\text { Number of } \\
\text { Flk } 1^{+} \text {cells on } \\
\text { day } 5\end{array}$ & $\begin{array}{c}\text { Number of } \\
\text { CD } 45^{+} \text {cells } \\
\text { on day } 10\end{array}$ & $\begin{array}{l}\text { Sox- } 2 \\
\text { expression on } \\
\text { day } 5 \text { relative } \\
\text { to Bruce } 4 \text { on } \\
\text { day } 0\end{array}$ & $\begin{array}{c}\text { Sox- } 2 \\
\text { expression on } \\
\text { day } 10 \\
\text { relative to } \\
\text { Bruce } 4 \text { on } \\
\text { day } 0\end{array}$ & $\begin{array}{l}\text { Oct- } 4 \\
\text { expression on } \\
\text { day } 5 \text { relative } \\
\text { to Bruce } 4 \text { on } \\
\text { day } 0\end{array}$ & $\begin{array}{c}\text { Oct- } 4 \\
\text { expression on } \\
\text { day } 10 \\
\text { relative to } \\
\text { Bruce } 4 \text { on } \\
\text { day } 0\end{array}$ & $\begin{array}{l}\text { Klf- } 4 \\
\text { expression on } \\
\text { day } 5 \text { relative } \\
\text { to Bruce } 4 \text { on } \\
\text { day } 0\end{array}$ & $\begin{array}{c}\text { Klf-4 } \\
\text { expression on } \\
\text { day } 10 \\
\text { relative to } \\
\text { Bruce } 4 \text { on } \\
\text { day } 0\end{array}$ \\
\hline & $\times 10^{5}$ & $\times 10^{5}$ & $\times 10^{-2}$ & $\times 10^{-2}$ & $\times 10^{-2}$ & $\times 10^{-2}$ & $\times 10^{-2}$ & $\times 10^{-2}$ \\
\hline J1 ES & 2.7 & 5.5 & 1.3 & 0.2 & 31 & 0.2 & 480 & 1.7 \\
\hline Bruce 4 ES & 3.2 & 23 & 0.5 & 0.04 & 41 & 0.08 & 32 & 0.04 \\
\hline MBM-iPS A & 3.1 & 10 & 1.0 & 6.3 & 2600 & 120 & 3600 & 83 \\
\hline MBM-iPS C & 2.2 & 0.1 & 18 & 1050 & 11000 & 2500 & 3700 & 700 \\
\hline MEF-iPS 1 & 2.6 & 7.3 & 16 & 21 & 12 & 56 & 3.2 & 5.8 \\
\hline MEF-iPS 5 & 4.0 & 18 & 45 & 71 & 0.65 & 70 & 22 & 5.6 \\
\hline
\end{tabular}

the lymphoid and myeloid compartments, but none of them could reconstitute hematopoiesis in secondary transfers, [56-59]. The question remains which kind of progenitor is developed under these conditions.

It has been shown that yolk sac progenitors display minimal HSC potential [60-62]. In contrast, para-aortic splanchnopleura-derived cells can give rise to bone marrow reconstituting HSC which are capable of definitive hematopoiesis [60, 61, 63]. It might be that ESC differentiation in vitro generates only HSC capable of primitive, but not of definitive hematopoietic potency. That would explain the inability of ESC-derived hematopoietic progenitors to generate HSC with the capacity to develop into lymphoid cells upon transplantation. This possibility ignores the fact that ESC and iPSC can be differentiated into primitive, that is, erythrocytes expressing fetal-type haemoglobin, and definitive cells, that is, lymphocytes, in vitro. HOXB4 overexpression in hematopoietic cells derived from ESC and from yolk sac enables the detection of transplantable HSC [47] (Figure 1). Hence, HOXB4 works in two ways. One is to increase the number of transplantable HSC. The second is to make HSC transplantable by modifying the homing receptors. Therefore, the injection of hematopoietic cells from human ESC directly into the bone marrow results in the detection of repopulatable HSC [49]. In conclusion, we need to understand the molecular program that induces this switch in greater detail to induce the formation of long-term reconstituting HSC with definitive hematopoietic potential, as HOXB4 does, but without retroviral insertion.

Finally, nonhematopoietic cells provide niches in bone marrow for the proper hematopoietic differentiation that are yet to be defined, and that are missing in the culture conditions of differentiating ESC. Furthermore, long-term repopulating HSC that reside in the bone marrow are in a deeply quiescent $\left(G_{0}\right)$ state and lose engraftment potential during their $S / G_{2} / M$ transit [64-67]. The present tissue culture conditions favor proliferation of HSC candidate cells. The development of conditions allowing cells to enter into and survive in the $G_{0} / G_{1}$ phase would be another important step towards establishing HSC in vitro.

\section{Conclusions}

Both stages of the in vitro development, first, from somatic, differentiated cells into iPSC and second, from iPSC into HSC are still so inefficient, even with murine cells, that the clinical use of human HSC derived from a patient's somatic cells are far from reality. It will need many more improvements at the various stages of reprogramming and differentiations of cells (Figure 1). Different somatic cell types represent different differentiation states, which have different growth abilities in vitro, different susceptibilities to be transduced by retroviral vectors and other yet unidentified factors, that make differently capable to become reprogrammed with different efficiencies. To allow effective reprogramming to iPSC, reversibly inducible or nonintegrative methods for reprogramming need to be used, since constitutive overexpression of reprogramming factors has been shown to interfere with differentiation. ES cells, and, to a lesser degree also, iPSC can be developed into all types of hematopoietic lineages in vitro. However, the reproducible generation of transplantable, engraftable HSC in vitro from pluripotent cells without overexpression of HOXB4 is still challenging (Figure 1).

\section{Conflict of Interests}

The authors have no conflicting financial interests.

\section{Acknowledgment}

The studies were supported by a grant from the MPG to F. Melchers.

\section{References}

[1] K. Takahashi and S. Yamanaka, "Induction of pluripotent stem cells from mouse embryonic and adult fibroblast cultures by defined factors," Cell, vol. 126, no. 4, pp. 663-676, 2006.

[2] K. Takahashi, K. Tanabe, M. Ohnuki et al., "Induction of pluripotent stem cells from adult human fibroblasts by defined factors," Cell, vol. 131, no. 5, pp. 861-872, 2007. 
[3] T. Aoi, K. Yae, M. Nakagawa et al., "Generation of pluripotent stem cells from adult mouse liver and stomach cells," Science, vol. 321, no. 5889, pp. 699-702, 2008.

[4] N. Maherali, R. Sridharan, W. Xie et al., "Directly reprogrammed fibroblasts show global epigenetic remodeling and widespread tissue contribution," Cell Stem Cell, vol. 1, no. 1, pp. 55-70, 2007.

[5] M. Nakagawa, M. Koyanagi, K. Tanabe et al., "Generation of induced pluripotent stem cells without Myc from mouse and human fibroblasts," Nature Biotechnology, vol. 26, no. 1, pp. 101-106, 2008.

[6] K. Okita, T. Ichisaka, and S. Yamanaka, "Generation of germline-competent induced pluripotent stem cells," Nature, vol. 448, no. 7151, pp. 313-317, 2007.

[7] M. Stadtfeld, N. Maherali, D. T. Breault, and K. Hochedlinger, "Defining molecular cornerstones during fibroblast to iPS cell reprogramming in mouse," Cell Stem Cell, vol. 2, no. 3, pp. 230-240, 2008.

[8] M. Wernig, A. Meissner, R. Foreman et al., "In vitro reprogramming of fibroblasts into a pluripotent ES-cell-like state," Nature, vol. 448, no. 7151, pp. 318-324, 2007.

[9] M. Pick, Y. Stelzer, O. Bar-Nur, Y. Mayshar, A. Eden, and N. Benvenisty, "Clone- and gene-specific aberrations of parental imprinting in human induced pluripotent stem cells," Stem Cells, vol. 27, no. 11, pp. 2686-2690, 2009.

[10] A. Doi, I. H. Park, B. Wen et al., "Differential methylation of tissue-and cancer-specific CpG island shores distinguishes human induced pluripotent stem cells, embryonic stem cells and fibroblasts," Nature Genetics, vol. 41, no. 12, pp. 13501353, 2009.

[11] M. Stadtfeld, E. Apostolou, H. Akutsu et al., "Aberrant silencing of imprinted genes on chromosome 12qF1 in mouse induced pluripotent stem cells," Nature, vol. 465, no. 7295, pp. 175-181, 2010.

[12] M. Quattrocelli, G. Palazzolo, G. Floris et al., "Intrinsic cell memory reinforces myogenic commitment of pericyte-derived iPSCs," Journal of Pathology, vol. 223, no. 5, pp. 593-603, 2011.

[13] M. H. Chin, M. Pellegrini, K. Plath, and W. E. Lowry, "Molecular analyses of human induced pluripotent stem cells and embryonic stem cells," Cell Stem Cell, vol. 7, no. 2, pp. 263 $269,2010$.

[14] Z. Ghosh, K. D. Wilson, Y. Wu, S. Hu, T. Quertermous, and J. C. Wu, "Persistent donor cell gene expression among human induced pluripotent stem cells contributes to differences with human embryonic stem cells," PLoS ONE, vol. 5, no. 2, Article ID e8975, 2010.

[15] M. G. Guenther, G. M. Frampton, F. Soldner et al., "Chromatin structure and gene expression programs of human embryonic and induced pluripotent stem cells," Cell Stem Cell, vol. 7, no. 2, pp. 249-257, 2010.

[16] M. C. N. Marchetto, G. W. Yeo, O. Kainohana, M. Marsala, F. H. Gage, and A. R. Muotri, "Transcriptional signature and memory retention of human-induced pluripotent stem cells," PLoS ONE, vol. 4, no. 9, Article ID e7076, 2009.

[17] K. D. Wilson, S. Venkatasubrahmanyam, F. Jia, N. Sun, A. J. Butte, and J. C. Wu, "MicroRNA profiling of human-induced pluripotent stem cells," Stem Cells and Development, vol. 18, no. 5, pp. 749-757, 2009.

[18] P. Neveu, M. J. Kye, S. Qi et al., "MicroRNA profiling reveals two distinct p53-related human pluripotent stem cell states," Cell Stem Cell, vol. 7, no. 6, pp. 671-681, 2010.
[19] S. K. Cho, T. D. Webber, J. R. Carlyle, T. Nakano, S. M. Lewis, and J. C. Zuniga-Pflucker, "Functional characterization of B lymphocytes generated in vitro from embryonic stem cells," Proceedings of the National Academy of Sciences of the United States of America, vol. 96, no. 17, pp. 9797-9802, 1999.

[20] T. Nakano, H. Kodama, and T. Honjo, "In vitro development of primitive and definitive erythrocytes from different precursors," Science, vol. 272, no. 5262, pp. 722-724, 1996.

[21] T. Nakano, H. Kodama, and T. Honjo, "Generation of lymphohematopoietic cells from embryonic stem cells in culture," Science, vol. 265, no. 5175, pp. 1098-1101, 1994.

[22] S. K. Cho and J. C. Zúñiga-Pflücker, "Development of lymphoid lineages from embryonic stem cells in vitro," Methods in Enzymology, vol. 365, pp. 158-169, 2003.

[23] Y. Wang, F. Yates, O. Naveiras, P. Ernst, and G. Q. Daley, "Embryonic stem cell-derived hematopoietic stem cells," Proceedings of the National Academy of Sciences of the United States of America, vol. 102, no. 52, pp. 19081-19086, 2005.

[24] A. L. Olsen, D. L. Stachura, and M. J. Weiss, "Designer blood: creating hematopoietic lineages from embryonic stem cells," Blood, vol. 107, no. 4, pp. 1265-1275, 2006.

[25] K. Matsumoto, T. Isagawa, T. Nishimura et al., "Stepwise development of hematopoietic stem cells from embryonic stem cells," PLoS ONE, vol. 4, no. 3, Article ID e4820, 2009.

[26] A. J. Potocnik, P. J. Nielsen, and K. Eichmann, "In vitro generation of lymphoid precursors from embryonic stem cells," EMBO Journal, vol. 13, no. 22, pp. 5274-5283, 1994.

[27] T. Nakano, "Lymphohematopoietic development from embryonic stem cells in vitro," Seminars in Immunology, vol. 7, no. 3, pp. 197-203, 1995.

[28] K. Seiler, M. Soroush Noghabi, K. Karjalainen, M. Hummel, F. Melchers, and M. Tsuneto, "Induced pluripotent stem cells expressing elevated levels of sox-2, oct-4, and klf-4 are severely reduced in their differentiation from mesodermal to hematopoietic progenitor cells," Stem Cells and Development, vol. 20, no. 7, pp. 1131-1142, 2011.

[29] J. B. Cibelli, S. L. Stice, P. J. Golueke et al., "Transgenic bovine chimeric offspring produced from somatic cell-derived stemlike cells," Nature Biotechnology, vol. 16, no. 7, pp. 642-646, 1998.

[30] M. J. Munsie, A. E. Michalska, C. M. O’Brien, A. O. Trounson, M. F. Pera, and P. S. Mountford, "Isolation of pluripotent embryonic stem cells from reprogrammed adult mouse somatic cell nuclei," Current Biology, vol. 10, no. 16, pp. 989992, 2000.

[31] S. Wakayama, M. L. Jakt, M. Suzuki et al., "Equivalency of nuclear transfer-derived embryonic stem cells to those derived from fertilized mouse blastocysts," Stem Cells, vol. 24, no. 9, pp. 2023-2033, 2006.

[32] M. J. Boland, J. L. Hazen, K. L. Nazor et al., "Adult mice generated from induced pluripotent stem cells," Nature, vol. 461, no. 7260, pp. 91-94, 2009.

[33] J. H. Hanna, K. Saha, and R. Jaenisch, "Pluripotency and cellular reprogramming: facts, hypotheses, unresolved issues," Cell, vol. 143, no. 4, pp. 508-525, 2010.

[34] K. Kim, A. Doi, B. Wen et al., "Epigenetic memory in induced pluripotent stem cells," Nature, vol. 467, no. 7313, pp. 285290, 2010.

[35] T. C. Doetschman, H. Eistetter, and M. Katz, "The in vitro development of blastocyst-derived embryonic stem cell lines: formation of visceral yolk sac, blood islands and myocardium," Journal of Embryology and Experimental Morphology, vol. 87, pp. 27-45, 1985. 
[36] G. Keller, M. Kennedy, T. Papayannopoulou, and M. V. Wiles, "Hematopoietic commitment during embryonic stem cell differentiation in culture," Molecular and Cellular Biology, vol. 13, no. 1, pp. 473-486, 1993.

[37] M. Wartenberg, J. Günther, J. Hescheler, and H. Sauer, "The embryoid body as a novel in vitro assay system for antiangiogenic agents," Laboratory Investigation, vol. 78, no. 10, pp. 1301-1314, 1998.

[38] A. M. Wobus, G. Wallukat, and J. Hescheler, "Pluripotent mouse embryonic stem cells are able to differentiate into cardiomyocytes expressing chronotropic responses to adrenergic and cholinergic agents and $\mathrm{Ca}^{2+}$ channel blockers," Differentiation, vol. 48, no. 3, pp. 173-182, 1991.

[39] R. M. Schmitt, E. Bruyns, and H. R. Snodgrass, "Hematopoietic development of embryonic stem cells in vitro: cytokine and receptor gene expression," Genes and Development, vol. 5, no. 5, pp. 728-740, 1991.

[40] M. V. Wiles and G. Keller, "Multiple hematopoietic lineages develop from embryonic stem (ES) cells in culture," Development, vol. 111, no. 2, pp. 259-267, 1991.

[41] K. Kulkeaw, Y. Horio, C. Mizuochi, M. Ogawa, and D. Sugiyama, "Variation in hematopoietic potential of induced pluripotent stem cell lines," Stem Cell Reviews and Reports, vol. 6, no. 3, pp. 381-389, 2010.

[42] K. Schenke-Layland, K. E. Rhodes, E. Angelis et al., "Reprogrammed mouse fibroblasts differentiate into cells of the cardiovascular and hematopoietic lineages," Stem Cells, vol. 26, no. 6, pp. 1537-1546, 2008.

[43] A. E. Grigoriadis, M. Kennedy, A. Bozec et al., "Directed differentiation of hematopoietic precursors and functional osteoclasts from human ES and iPS cells," Blood, vol. 115, no. 14, pp. 2769-2776, 2010.

[44] F. Soldner, D. Hockemeyer, C. Beard et al., "Parkinson's disease patient-derived induced pluripotent stem cells free of viral reprogramming factors," Cell, vol. 136, no. 5, pp. 964-977, 2009.

[45] H. Zhou, S. Wu, J. Y. Joo et al., "Generation of induced pluripotent stem cells using recombinant proteins," Cell Stem Cell, vol. 4, no. 5, pp. 381-384, 2009.

[46] L. Warren, P. D. Manos, T. Ahfeldt et al., "Highly efficient reprogramming to pluripotency and directed differentiation of human cells with synthetic modified mRNA," Cell Stem Cell, vol. 7, no. 5, pp. 618-630, 2010.

[47] M. Kyba, R. C. R. Perlingeiro, and G. Q. Daley, "HoxB4 confers definitive lymphoid-myeloid engraftment potential on embryonic stem cell and yolk sac hematopoietic progenitors," Cell, vol. 109, no. 1, pp. 29-37, 2002.

[48] S. Bonde, K. M. Chan, and N. Zavazava, "ES-cell derived hematopoietic cells induce transplantation tolerance," PLoS ONE, vol. 3, no. 9, Article ID e3212, 2008.

[49] L. Wang, P. Menendez, F. Shojaei et al., "Generation of hematopoietic repopulating cells from human embryonic stem cells independent of ectopic HOXB4 expression," Journal of Experimental Medicine, vol. 201, no. 10, pp. 1603-1614, 2005.

[50] S. Bonde, A. M. Dowden, K. M. Chan, W. B. Tabayoyong, and N. Zavazava, "HOXB4 but not BMP4 confers selfrenewal properties to ES-derived hematopoietic progenitor cells," Transplantation, vol. 86, no. 12, pp. 1803-1809, 2008.

[51] K. M. Chan, S. Bonde, H. Klump, and N. Zavazava, "Hematopoiesis and immunity of HOXB4-transduced embryonic stem cell derived hematopoietic progenitor cells," Blood, vol. 111, no. 6, pp. 2953-2961, 2008.
[52] S. Pilat, S. Carotta, B. Schiedlmeier et al., "HOXB4 enforces equivalent fates of ES-cell-derived and adult hematopoietic cells," Proceedings of the National Academy of Sciences of the United States of America, vol. 102, no. 34, pp. 12101-12106, 2005.

[53] K. M. Bowles, L. Vallier, J. R. Smith, M. R. J. Alexander, and R. A. Pedersen, "HOXB4 overexpression promotes hematopoietic development by human embryonic stem cells," Stem Cells, vol. 24, no. 5, pp. 1359-1369, 2006.

[54] S. J. Lu, Q. Feng, Y. Ivanova et al., "Recombinant HoxB4 fusion proteins enhance hematopoietic differentiation of human embryonic stem cells," Stem Cells and Development, vol. 16, no. 4, pp. 547-559, 2007.

[55] X. B. Zhang, B. C. Beard, G. D. Trobridge et al., "High incidence of leukemia in large animals after stem cell gene therapy with a HOXB4-expressing retroviral vector," Journal of Clinical Investigation, vol. 118, no. 4, pp. 1502-1510, 2008.

[56] N. Hole, G. J. Graham, U. Menzel, and J. D. Ansell, "A limited temporal window for the derivation of multilineage repopulating hematopoietic progenitors during embryonal stem cell differentiation in vitro," Blood, vol. 88, no. 4, pp. 1266-1276, 1996.

[57] A. M. Muller and E. A. Dzierzak, "ES cells have only a limited lymphopoietic potential after adoptive transfer into mouse recipients," Development, vol. 118, no. 4, pp. 1343-1351, 1993.

[58] A. J. Potocnik, G. Nerz, H. Kohler, and K. Eichmann, "Reconstitution of B cell subsets in rag deficient mice by transplantation of in vitro differentiated embryonic stem cells," Immunology Letters, vol. 57, no. 1-3, pp. 131-137, 1997.

[59] T. Miyagi, M. Takeno, H. Nagafuchi, M. Takahashi, and N. Suzuki, "Flk1+ cells derived from mouse embryonic stem cells reconstitute hematopoiesis in vivo in SCID mice," Experimental Hematology, vol. 30, no. 12, pp. 1444-1453, 2002.

[60] A. Cumano, J. C. Ferraz, M. Klaine, J. P. Di Santo, and I. Godin, "Intraembryonic, but not yolk sac hematopoietic precursors, isolated before circulation, provide long-term multilineage reconstitution," Immunity, vol. 15, no. 3, pp. 477-485, 2001.

[61] A. Cumano, F. Dieterlen-Lievre, and I. Godin, "Lymphoid potential, probed before circulation in mouse, is restricted to caudal intraembryonic splanchnopleura," Cell, vol. 86, no. 6, pp. 907-916, 1996.

[62] I. M. Samokhvalov, N. I. Samokhvalova, and S. I. Nishikawa, "Cell tracing shows the contribution of the yolk sac to adult haematopoiesis," Nature, vol. 446, no. 7139, pp. 1056-1061, 2007.

[63] A. Medvinsky and E. Dzierzak, "Definitive hematopoiesis is autonomously initiated by the AGM region," Cell, vol. 86, no. 6, pp. 897-906, 1996.

[64] M. B. Bowie, K. D. McKnight, D. G. Kent, L. McCaffrey, P. A. Hoodless, and C. J. Eaves, "Hematopoietic stem cells proliferate until after birth and show a reversible phasespecific engraftment defect," Journal of Clinical Investigation, vol. 116, no. 10, pp. 2808-2816, 2006.

[65] W. H. Fleming, E. J. Alpern, N. Uchida, K. Ikuta, G. J. Spangrude, and I. L. Weissman, "Functional heterogeneity is associated with the cell cycle status of murine hematopoietic stem cells," Journal of Cell Biology, vol. 122, no. 4, pp. 897-902, 1993.

[66] H. Glimm, I. H. Oh, and C. J. Eaves, "Human hematopoietic stem cells stimulated to proliferate in vitro lose engraftment potential during their S/G2/M transit and do not reenter Go," Blood, vol. 96, no. 13, pp. 4185-4193, 2000. 
[67] H. K. Habibian, S. O. Peters, C. C. Hsieh et al., "The fluctuating phenotype of the lymphohematopoietic stem cell with cell cycle transit," Journal of Experimental Medicine, vol. 188, no. 2, pp. 393-398, 1998. 

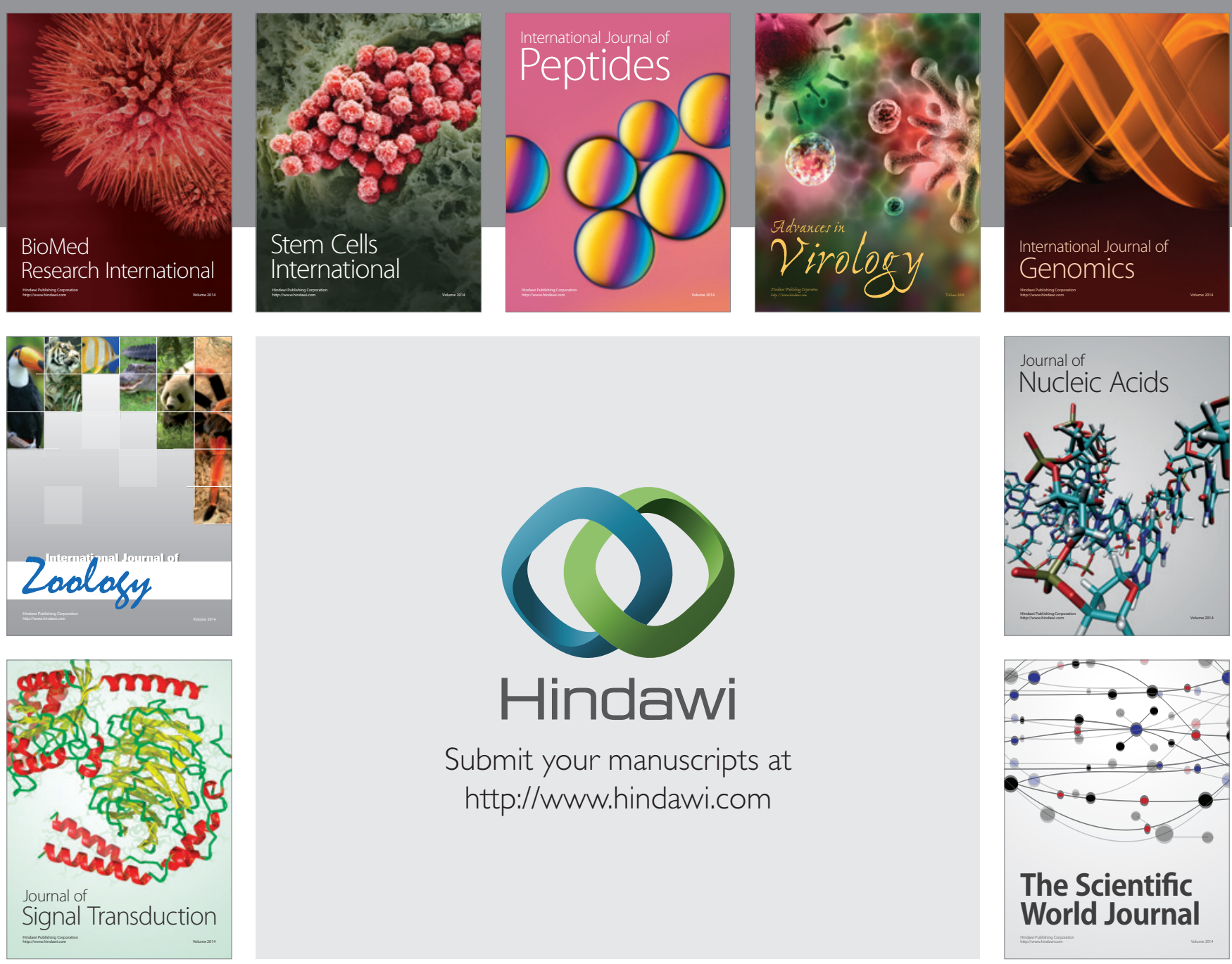

Submit your manuscripts at

http://www.hindawi.com
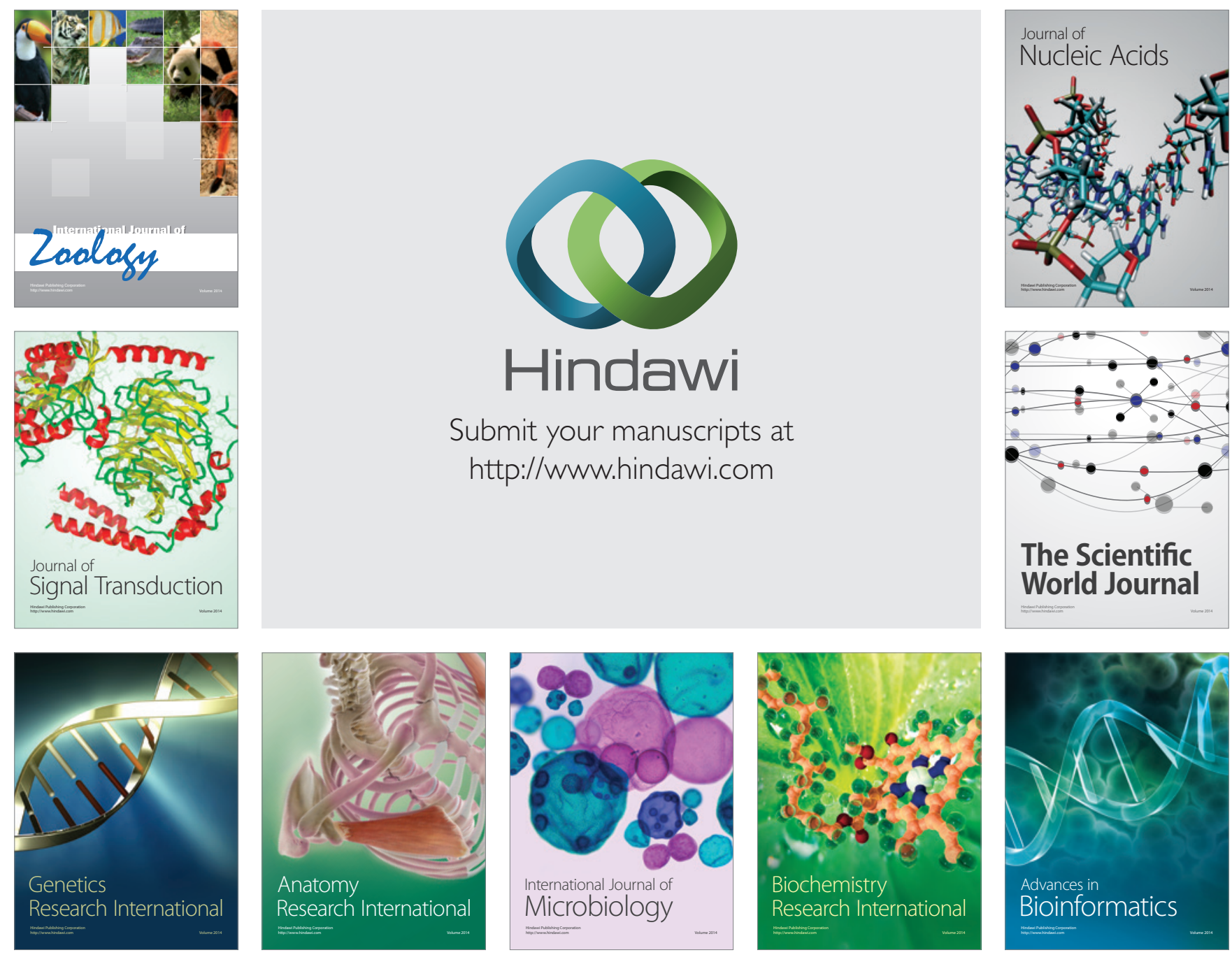

The Scientific World Journal
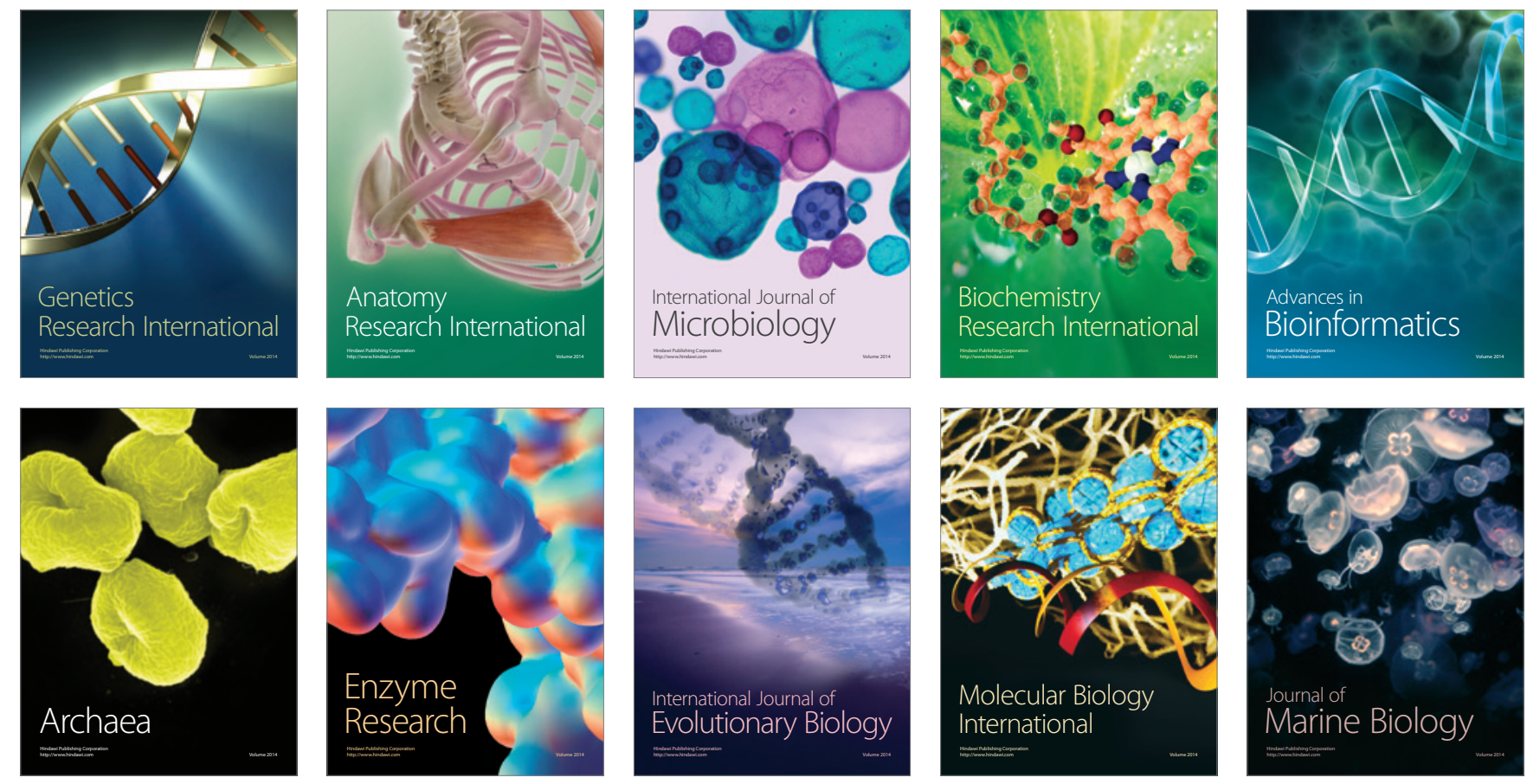